\title{
Moneda, armas y objetos suntuarios: el tesoro de los reyes de Portugal en los primeros dos siglos de su existencia
}

\author{
Ana Maria S. A. Rodrigues \\ Universidade de Lisboa \\ Faculdade de Letras \\ anarodrigues@letras.ulisboa.pt
}

\begin{abstract}
RESUMEN
El objetivo de este texto es hacer una primera aproximación a la composición y evolución del tesoro regio desde la muerte del primer rey de Portugal, Alfonso Enríquez, en 1185, hasta la del último monarca de la primera dinastía, Fernando I, en 1383. Se constata que, en esos dos siglos, disminuye la importancia de las sumas de oro y plata y de las armas, y crece la de los objetos suntuarios entre los bienes muebles que los monarcas y sus esposas transmiten a sus herederos y con los que agracian a sus oficiales, sus dependientes y los monasterios e iglesias de los que son patronos.
\end{abstract}

Palabras clave: Tesoro, armas, joyas, vajilla de plata, relicarios.

\section{Coins, Weapons, and Sumptuary Objects: The Treasury of the Monarchs of Portugal in the First Two Centuries of Its Existence}

\begin{abstract}
The aim of this paper is to make a first approach to the composition and evolution of the royal treasure from the death of the first king of Portugal, Afonso Henriques, in 1185, to the death of the last king of the first dynasty, Fernando I, in 1383. During these two centuries, The importance of coins, precious metals and armoury decreases among the mobile goods the kings and their wives transmit to their heirs, and offer to their officials, their dependents, and the monasteries and churches they protect as patrons; the relevance of sumptuary objects grows accordingly.
\end{abstract}

Key words: Treasury, armoury, jewels, silver tableware, reliquaries. 
En Portugal, los objetos suntuarios del período medieval conservados en museos son muy escasos y pertenecen, en su mayoría, a iglesias y monasterios; no hay entre ellos joyas, vajilla de plata ni prendas de vestir laicas. Tampoco se han podido encontrar en los archivos los libros de cuentas, inventarios y libros de registro de entrada y salida de objetos del tesoro regio que existen en abundancia en otros reinos peninsulares ${ }^{1}$. Eso explica que, al igual que los historiadores del arte, los historiadores portugueses de la economía o de la vida material no se hayan interesado hasta nuestros días por el estudio de ese elemento fundamental de la monarquía. Con todo, los testamentos de los reyes y de las reinas, al igual que algunos contratos matrimoniales, cartas de dote, donaciones a casas religiosas o a particulares y otros documentos nos permiten conocer algunos aspectos de ese tesoro en la diacronía. Así, en este texto y a partir de tales fuentes intentaremos hacer una primera aproximación a la composición y evolución del tesoro regio durante la primera dinastía portuguesa, o sea, desde Alfonso Enríquez hasta Fernando I. ${ }^{234}$

\begin{tabular}{|c|c|}
\hline \multicolumn{2}{|c|}{ Reyes de Portugal de la primera dinastía y sus esposas } \\
\hline $\begin{array}{c}\text { Alfonso I (Alfonso Enríquez) } \\
\left(1109-\mathrm{a}^{2}{ }^{1128-1185)}\right.\end{array}$ & 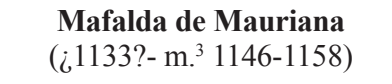 \\
\hline $\begin{array}{c}\text { Sancho I } \\
(1154-\text { a. 1185-1211) }\end{array}$ & $\begin{array}{c}\text { Dulce de Aragón y Barcelona } \\
\text { ([1153-59]-m. 1174-1198) }\end{array}$ \\
\hline $\begin{array}{c}\text { Alfonso II } \\
(1186-a .1211-1223)\end{array}$ & $\begin{array}{c}\text { Urraca de Castilla } \\
([1186-87]-\mathrm{m} .1208-1220)\end{array}$ \\
\hline $\begin{array}{c}\text { Sancho II } \\
\text { ([1209-10]-a. 1223-1248) }\end{array}$ & $\begin{array}{c}\text { Mencía López de Haro } \\
\text { (¿1215?-m. ¿1244?-[1270-71]) }\end{array}$ \\
\hline $\begin{array}{c}\text { Alfonso III } \\
(1217-\text { a. } 1248-1279)\end{array}$ & $\begin{array}{c}\text { Beatriz Alfonso [de Castilla] } \\
\quad(1244-\mathrm{m} .1253-1300)\end{array}$ \\
\hline $\begin{array}{c}\text { Denis } \\
(1261-\text {-a. } 1279-1325)\end{array}$ & $\begin{array}{c}\text { Isabel de Aragón } \\
(¿ 1271 ?-\mathrm{m} .1281-1336)\end{array}$ \\
\hline $\begin{array}{c}\text { Alfonso IV } \\
(1291-\text { a. 1325-1357) }\end{array}$ & $\begin{array}{l}\text { Beatriz de Castilla } \\
(1293-\mathrm{m} .1309-1359)\end{array}$ \\
\hline \multicolumn{2}{|l|}{$\begin{array}{c}\text { Pedro I }{ }^{4} \\
(1320-\text { a. } 1357-1367)\end{array}$} \\
\hline $\begin{array}{c}\text { Fernando I } \\
(1345-\text {-a. } 1367-1383)\end{array}$ & $\begin{array}{l}\text { Leonor Tales de Meneses } \\
\left(¿ 1350 ?-\mathrm{m} .1372-\iota_{1410}\right)\end{array}$ \\
\hline
\end{tabular}

1 Las rarísimas excepciones a esta afirmación serán referidas en el decurso de este texto.

2 Data de la subida al trono.

3 Data del matrimonio con el infante heredero o el monarca portugués.

${ }^{4}$ Este rey, viudo cuando subió al trono, había estado prometido a Blanca de Castilla, casado con Constanza Manuel y amancebado o casado con Inés de Castro. 


\section{El tesoro monetario}

Lo que resalta con más claridad de los testamentos de los primeros reyes de Portugal es la importancia, en el tesoro regio, de los metales preciosos, amonedados o no. En 1179, Alfonso I lega por su alma, para repartir por viudas, huérfanos, las obras de varias instituciones religiosas y para liberar cautivos, $\operatorname{los} 22.000$ morabetinos $^{5}$ que tiene guardados en el Monasterio de Santa Cruz de Coímbra ${ }^{6}$. Este monasterio, fundado en 1131 por miembros del cabildo de la catedral de Coímbra y afiliado a la Orden de los Canónigos Regulares de San Agustín, fue desde el inicio patrocinado por el monarca, que costeó su edificación y le concedió innúmeros bienes raíces y privilegios? La confianza que tiene en la solidez de las defensas de la ciudad del Mondego, pero también en la protección divina y en la probidad de los priores y canónigos del monasterio, explican que Alfonso Enríquez les confie la guardia de su tesoro monetario.

Cerca de diez años más tarde, en su primer testamento, su hijo Sancho I deja 150 marcos ${ }^{8}$ de plata para que sean hechos cálices para todas las iglesias bajo la advocación de Santa María y Santiago de su reino, y refiere tener 10.000 morabetinos guardados en Coímbra y Évora ${ }^{9}$. Sin embargo, es en su segundo testamento, de $1210^{10}$, donde el monarca revela su inmensa fortuna móvil: tiene, como mínimo, 250.000 morabetinos, 195 marcos con 4 onzas y media de oro y 100 marcos de plata guardados en las torres de Coímbra; 6.000 morabetinos más en Évora (¿con los frailes locales? $\left.{ }^{11}\right) ; 20.000$ morabetinos con los Templarios en Tomar, 36.000 morabetinos con los Hospitalarios en Belver, 150 marcos de plata y 40.000 morabetinos en el Monasterio de Alcobaça ${ }^{12}$. En los legados que hace a sus hijos e hijas, tanto a los legítimos como a los bastardos, menciona además marcos de plata guardados en Leiria ${ }^{13}$.

5 El morabetino era una moneda corriente de oro correspondiente al dinar musulmán. Los primeros morabetinos portugueses fueron acuñados en tiempos de Sancho I pero, con anterioridad, circulaban en Portugal morabetinos de otros reinos cristianos peninsulares y monedas de oro musulmanas. Cfr. M.G. MARQUES, História da moeda medieval portuguesa, Sintra, 1996, pp. 36-40.

6 Documentos Medievais Portugueses. Documentos régios. Vol. I-Documentos dos condes portugalenses e de D. Afonso Henriques, A. D. 1095-1185, t. I, Lisboa, 1958, doc. 334, p. 436.

7 A.A. MARTINS, O Mosteiro de Santa Cruz de Coimbra na Idade Média, Lisboa, 2003, pp. 190-202.

8 El marco era una unidad ponderal para metales que valía 230 gramos; se subdividía en 8 onzas, 16 ochavas y 1152 granos. A.H.O. MARQUES, "Pesos e medidas", J. SERRÃO (dir.), Dicionário de História de Portugal, vol. V, Oporto, 1975, p. 70.

9 El documento fue datado de [1188, después del 24 de marzo] por R. AZEVEDO, A.J. COSTA y M.R. PEREIRA, Documentos de Sancho I (1174-1367), Coimbra, 1979, doc. 30, pp. 47-48.

10 Ibid., doc. 194, pp. 297-301.

11 Évora fue conquistada por los portugueses en 1165 y se quedó aislada en territorio musulmán después de la incursión almohade de 1174, que repuso la frontera en el curso del Tajo. En 1175 o 1176, Alfonso I creó la Orden militar de Évora para asegurar la defensa de la ciudad. Los frailes de Évora transfirieron más tarde su sede a Avis y fueron conocidos en adelante como Orden de Avis. J. MATTOSO, D. Afonso Henriques, Lisboa, 2007, pp. 344-346.

12 Este monasterio fue también fundado por Alfonso I en 1153 y entregado a los cistercienses de Claraval. Sancho I acrecentó mucho su dominio señorial. P. PENTEADO, "Alcobaça", C.M. AZEVEDO (dir.), Dicionário de História Religiosa de Portugal, vol. A-C, Lisboa, 2000, pp. 32-33.

13 S.A. GOMES, Introdução à história do castelo de Leiria, Leiria, 2004, p. 115. Cfr. también S.A. GOMES, "Para uma história leiriense. XI. Q - Nótula sobre tesouros régios na Leiria medieval", Região de Leiria, 2.XI.1984. 


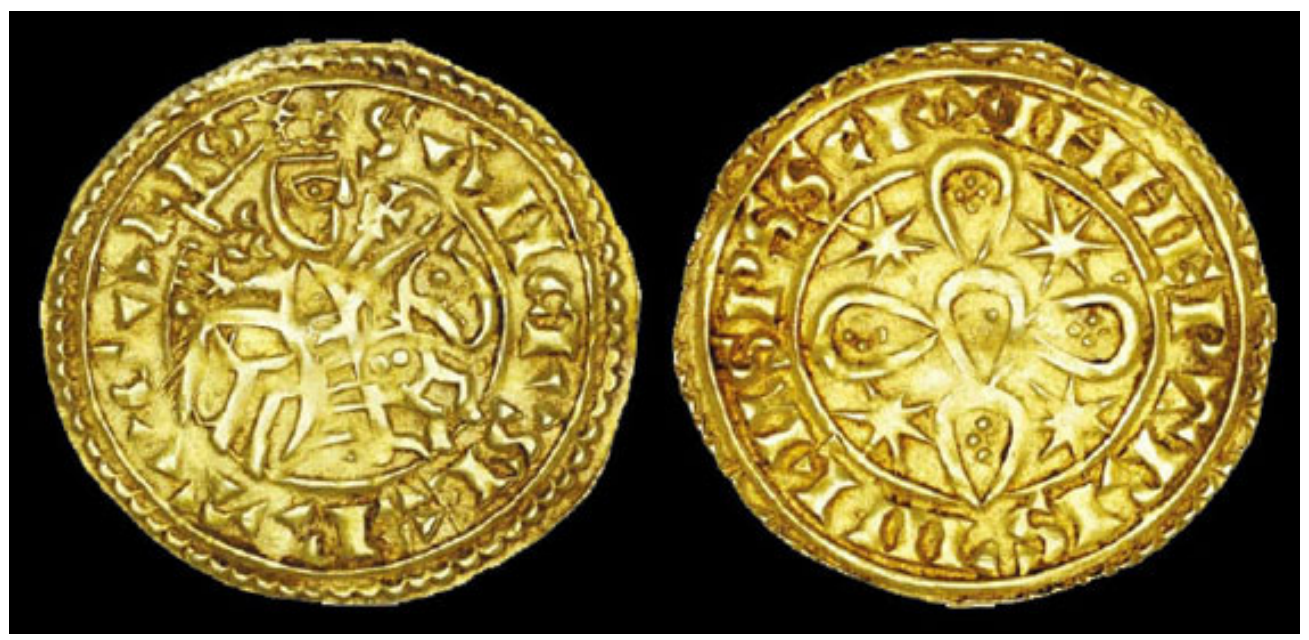

Fig. 1. Morabetino de Sancho I, siglos XII-XIII (Lisboa, Museo del Banco de Portugal).

El problema con los testamentos es que casi nunca sabemos si el testador está repartiendo toda su fortuna o solamente lo que le queda de libre disposición después de retiradas las herencias obligatorias. Desde este punto de vista, los testamentos de Alfonso II son muy claros: en los dos primeros, de 1214 y 1218 , el rey refiere que la mitad de sus bienes muebles pertenece a su esposa, la reina Urraca; con la otra mitad, ordena que se paguen todas sus deudas y lo que quede se divida en tres partes, dos para repartir igualitariamente entre sus hijos e hijas legítimos, como determinaba el derecho sucesorio, y una para distribuir por su alma ${ }^{14}$. Urraca de Castilla, que testó igualmente en 1214 , hizo la misma repartición de su fortuna ${ }^{15}$. Sin embargo, como fue la reina la primera a morir, en 1220, en su último testamento, datado del año siguiente, el rey dispuso de la totalidad de sus bienes muebles. Entre ellos, constaban los morabetinos y dineros ${ }^{16}$ que había heredado de su padre (algunos de los cuales seguían guardados en el Monasterio de Alcobaça), pero también, según sus palabras, oro no amonedado y plata, amonedada o no, cuya cantidad y lugar de depósito omite $^{17}$.

14 A.J. COSTA, "Os mais antigos documentos escritos em português. Revisão de um problema históricolinguístico", Estudos de cronologia. Diplomática paleografia e histórico-linguísticos, Oporto, 1992, doc. 6, pp. 227-235; M.T.N. VELOSO, D. Afonso II. Relações de Portugal com a Santa Sé durante o seu reinado, Coímbra, 2000, doc. 1b, pp. 279-282.

15 A.C. SOUSA, Provas da história genealógica da Casa Real portuguesa, t. I, liv. I-II, Coímbra, 1946 , pp. 47-49.

16 El dinero podía ser una subdivisión de la libra, moneda de cuenta, pero era también, como en este caso, una moneda corriente de plata acuñada por los monarcas de los reinos cristianos peninsulares. Sobre los dineros portugueses, emitidos desde Alfonso I hasta Alfonso III y sustituidos en tiempos de este rey por los dineros nuevos o alfonsís, cfr. M.G. MARQUES, op. cit., 1996, pp. 52-71.

17 A.C. SOUSA, op. cit., 1946, pp. 43-46. 
Es también este monarca el que nos explica con algún detalle de dónde le venía tanta riqueza en metales preciosos. En general, los historiadores atribuyen la abundancia de oro y plata en los reinos ibéricos a la guerra contra los musulmanes, que proporcionaba saqueos, rescates y el pago de tributos por los pueblos sometidos; las relaciones comerciales pacíficas que perduraron a pesar de los episodios bélicos también hacían llegar monedas musulmanas a los reinos cristianos del Norte ${ }^{18}$. Alfonso II, empero, afirma que lo que tenía en distintos tesoros por el reino, aparte de lo que estaba en Alcobaça, era el producto de las décimas de las luctuosas, de las armas y de otras décimas que no detalla, o sea, los derechos reales que recaían, entre otras cosas, sobre las herencias y el servicio militar de sus vasallos ${ }^{19}$.

A estos dos derechos reales añade Sancho II uno más en su primer testamento, de data desconocida pero anterior a 1231: el que incidía sobre la acuñación de la moneda y era pagado por los monederos del reino en el mes de mayo de cada año; pero el soberano no solo no parece seguro de que este tributo sea suficiente para pagar todas sus mandas como reconoce que algunas de su padre siguen por cumplir ${ }^{20}$. El auge de la abundancia en metales preciosos es cosa del pasado y se adivinan dificultades financieras para la monarquía.

Estas se agravarán durante el reinado del mismo Sancho, caracterizado a partir de 1236 por un clima de desorden y violencia que dificultará la recaudación fiscal, y por enormes conflictos con la Iglesia que culminarán con la destitución del rey por el papa Inocencio IV en 1245, y su sustitución por su hermano Alfonso, conde de Boloña ${ }^{21}$. Sancho II acabó perdiendo la guerra civil subsiguiente y se refugió en Toledo en 1247. En su segundo y último testamento, datado de algunos días antes de su muerte, en enero de 1248, el rey exiliado distribuye 5.000 aureos $^{22}$ entre los miembros de su domesticidad y bienes raíces entre sus casas religiosas preferidas y sus fieles ${ }^{23}$. Sin embargo, es legítimo dudar que Sancho aún tuviera consigo todo ese dinero y pudiera legítimamente conceder bienes pertenecientes a la corona cuando esta ya le había sido retirada ${ }^{24}$.

Su hermano y sucesor Alfonso III tampoco recurre a algún tesoro monetario para pagar sus mandas en el momento de su muerte. Lo que no quiere decir que no poseyera ninguno: existe un registro de las cuantías entradas y salidas del que seguía depositado en el Monasterio de Santa Cruz de Coímbra entre 1261 y $1265^{25}$. Ese tesoro

18 A.H.O. MARQUES, “A circulação e a troca de produtos”, M.H.C. COELHO y A.L.C. HOMEM (coords.), Portugal em definição de fronteiras do condado portucalense à crise do século XIV, vol. III de J. SERRÃO y A.H.O. MARQUES (dirs.), Nova História de Portugal, Lisboa, 1996, p. 524.

19 Sabemos, por otras fuentes, que los otros derechos reales eran la justicia, la acuñación de la moneda y los yantares. J. MATTOSO, Identificação de um país. Ensaio sobre as origens de Portugal, vol. II, Lisboa, 1983, p. 93.

20 A.C. SOUSA, op. cit., 1946, pp. 61-63.

21 H. FERNANDES, D. Sancho II, Lisboa, 2006, pp. 219-262.

22 No se trata de una moneda de cuenta ni de una moneda corriente, pero sí, probablemente, de una alusión a la moneda de oro en circulación, el morabetino.

23 A.C. SOUSA, op. cit., 1946, pp. 63-64.

24 Como ya ha señalado H. FERNANDES, op. cit., 2006, p. 19.

25 P. AZEVEDO, "O tesouro de D. Afonso III no mosteiro de Santa Cruz de Coimbra”, Boletim de Segunda Classe da Academia de Ciências de Lisboa, 7 (1913), pp. 233-263. 
estaba guardado en arcas que solo se abrían con tres llaves usadas simultáneamente, de las que una estaba en poder del prior del monasterio, otra la tenía el almojarife de Coímbra y la tercera la confiaba el rey a quien enviaba a Coímbra a buscar el dinero; las especies monetarias atesoradas eran dineros portugueses viejos y nuevos, pipiones de Castilla y dineros leoneses, burgaleses, salmantinos y turonenses. Por lo menos en parte, esta riqueza provenía de la acuñación de moneda, que seguía haciéndose en Coímbra ${ }^{26}$. Sin embargo, en 1271, al dictar sus últimas voluntades, Alfonso III no refiere ni sus bienes muebles ni su tesoro y obliga al cumplimiento de sus mandas las rentas de la ciudad de Lisboa, incluyendo expresamente las de su puerto y de su término rural; solo cuando todo esté pagado podrán dichas rentas revertir de nuevo para la corona ${ }^{27}$. Esto quiere decir que todo el costo de la salvación del alma del monarca recaería sobre su sucesor.

Sin embargo, en 1299, data del primer testamento de Denis ${ }^{28}$, las deudas y mandas de su padre siguen impagadas y el rey moviliza todos sus bienes muebles para pagarlas, tanto esas como las suyas propias, mencionando oro y plata, trabajada o no; moneda guardada en las torres de Coímbra, Lisboa y otros lugares no especificados; esclavos, animales, joyas, tejidos y todo lo más que se encuentre. Estos bienes muebles serán transformados en dinero para llevar a cabo las ceremonias fúnebres del monarca, celebrar misas perpetuas por su alma, beneficiar monasterios e iglesias, y con lo remanente libertar cautivos, construir hospitales y casar doncellas pobres. Pero como teme que no sea lo suficiente, Denis obliga a ello no solo las rentas de Lisboa, como había hecho su padre (con el consabido resultado nulo), sino también las de Santarém, y ordena a su hijo, bajo pena de su maldición, que contribuya además con la primera moneda que los pueblos del reino suelen pagar al nuevo rey cuando empieza a reinar.

En su segundo instrumento de últimas voluntades, de $1322^{29}$, todo sigue por pagar pero el monarca es más preciso en cuanto al metálico que posee e informa de que en la torre albarrana del castillo de Lisboa ha hecho reunir, para el bien de su alma y la defensa de su reino, 350.000 libras de dineros portugueses ${ }^{30}$ que deberán ser dadas en totalidad a sus testamentarios para cumplir sus mandas. Esto le permite prescindir de las rentas de Lisboa y de Santarém, y de la primera moneda del reinado de su hijo, que ya no son referidas.

En su tercer y último testamento de $1324^{31}$, la situación es la misma, con la excepción de que el rey admite ahora la posibilidad de que a su muerte estén guardadas en su tesoro más que las 350.000 libras que había reservado para cumplir su testamento, legando el resto a su hijo heredero. A lo largo del reinado de Denis, la situación

26 Ibid., p. 232.

27 A.C. SOUSA, op. cit., 1946, pp. 69-73.

28 F. BRANDÃO, Monarquia Lusitana, vol. 5, Lisboa, 1976 [ed. original: 1652], Apêndice, Escritura 34, pp. 329-331.

29 A.C. SOUSA, op. cit., 1946, pp. 125-132.

30 La libra es una moneda de cuenta, utilizada para definir valores muy altos. Los "dineros portugueses" referidos por el rey son, probablemente, los dineros "nuevos" emitidos por su padre Alfonso III y por él mismo, o sea una moneda corriente de plata. Cf. M.G. MARQUES, op. cit., pp. 72-

31 F. BRANDÃO, Monarquia Lusitana, vol. 6, Lisboa, 1980 [ed. original: 1672], pp. 582-589. 
económica mejoró y el soberano pudo acumular grandes cantidades de metálico; sin embargo, eso no lo estimuló a cumplir el testamento de su padre ni a reembolsar sus propias deudas, dejando esos pesados encargos a su sucesor.

Desgraciadamente, no podemos saber cómo solucionó Alfonso IV este problema porque lo que tradicionalmente se llama su testamento es, en realidad, el diploma de fundación de su capilla en la Catedral de Lisboa y del hospital asociado; no tiene ninguna cláusula referente al nombramiento de su sucesor, la repartición de sus bienes o el pagamiento de sus deudas ${ }^{32}$. Ignoramos, así, cómo proveyó a sus ceremonias fúnebres y qué dejó a su sucesor, sus otros hijos y sus dependientes.

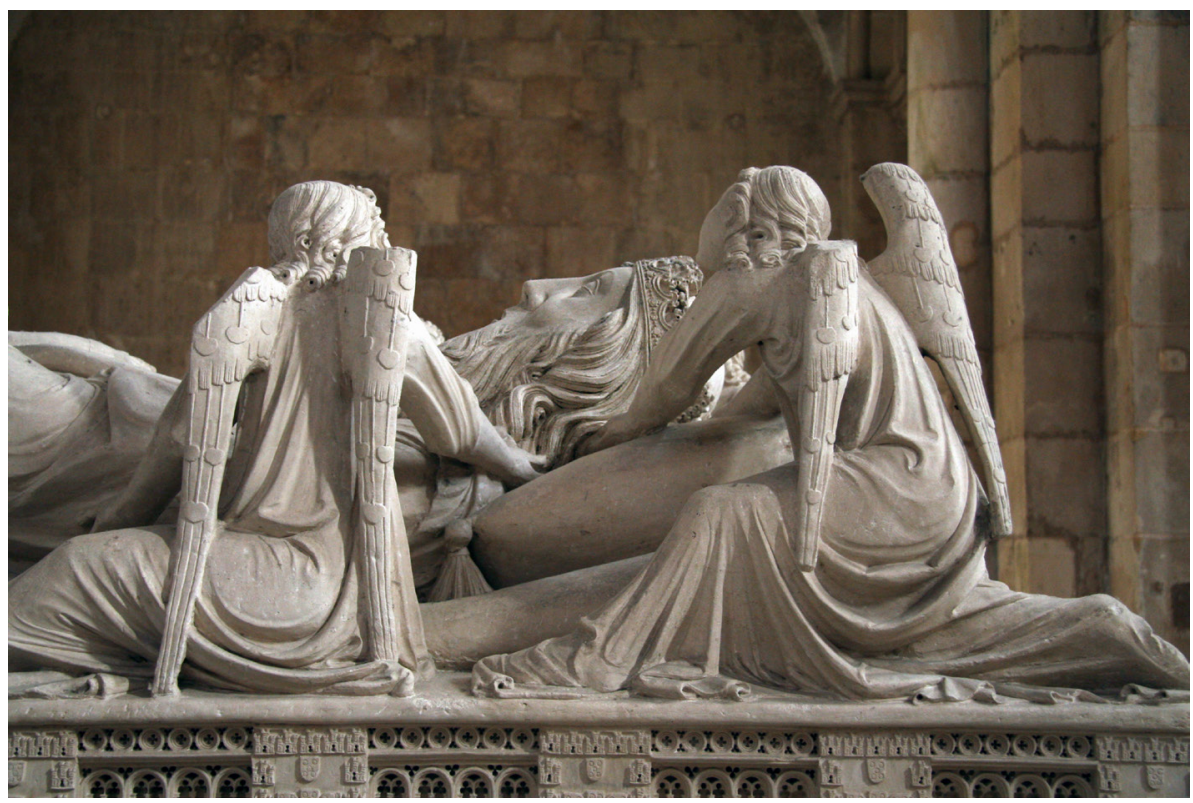

Fig. 2. Túmulo de Pedro I, 1361-1366 (Monasterio de Alcobaça).

El testamento de su hijo Pedro I (Fig. 2), en compensación, revela que este rey se había adueñado de los bienes que sus mujeres Constanza Manuel e Inés de Castro ${ }^{33}$ habían dejado para la salvación de sus almas, sin cumplir sus mandas ${ }^{34}$; los deja ahora a los testamentarios de esas damas para que las cumplan. Como no dice nada sobre Alfonso IV, podemos suponer que había hecho ya todo lo que su padre le dejara encargado. En lo demás, se limita a quitar deudas a dos criados suyos y a dejar cantidades variables de dinero a sus hijos -María (hija de Constanza), Beatriz, Juan,

32 A.C. SOUSA, op. cit., 1946, pp. 335-341.

33 El hecho de que el rey se hubiera casado con Inés es, como se sabe, controvertido; el más reciente estado de la cuestión sobre su vida matrimonial ha sido publicado por A.P.M. COSTA, "As três mulheres de D. Pedro I", V.L. MENINO y A.P.M. COSTA, A rainha, as infantas e a aia, Lisboa, 2012, pp. 215-458.

34 No sabemos cuáles son porque los testamentos de estas dos damas, desgraciadamente, se han perdido. 
Denis (hijos de Inés) y una niña cuyo nombre se silencia y era criada en el Monasterio de Santa Clara de Coímbra-, movilizando para ello el tercio de libre disposición de su fortuna; lo que quede después de pagadas estas mandas será dado a pobres. Pero el soberano añade: "en los otros bienes del Reino sea heredero el dicho infante Don Fernando nuestro hijo" 35 . Es la primera vez que se establece una diferencia nítida entre los bienes del rey y los bienes del reino, siendo los primeros repartidos por los herederos obligatorios y las personas e instituciones que el rey quiere beneficiar, cabiendo los segundos, en exclusivo, al primogénito.

En cuanto a Fernando I, en su testamento de 1378, aparte de regular la sucesión del reino, también se refiere solo al tercio de los bienes de que podía disponer libremente, dejándolo para pagar sus deudas y, con el remanente, casar huérfanos y liberar cautivos; se trata de dinero, oro, plata, joyas y otros bienes muebles, pero el rey no especifica tipos, cantidades, ni dónde los tiene guardados ${ }^{36}$. En 1383, poco antes de morir, Fernando instituye también una capilla con su esposa Leonor Teles ${ }^{37}$, sin revelar nada más sobre el tesoro regio en esos años.

\section{Animales y esclavos}

Además de moneda y cantidades de oro y plata, los soberanos también legaron bienes semovientes: animales y esclavos, a los que se atribuía el mismo estatuto legal, negando a los segundos la dignidad humana ${ }^{38}$. En su primer testamento, de $1176^{39}$, Alfonso Enríquez dejó al maestro y a los frailes de Évora todas sus bestias de carga y sus moros de Santarém y Lisboa; al Monasterio de Santa Cruz de Coímbra, un moro orfebre, otro carpintero y otro sastre; a este monasterio y al de Alcobaça, su ganado de por medias; y a su hija ilegítima Urraca Alfonso sus moras de Coímbra. En el segundo testamento, ya referido, de 1178, legó a Santa Cruz todos sus moros, caballos y acémilas. En estos casos, podemos hacer la identificación de "moros" con esclavos porque existía ya la denominación de moros forros para los musulmanes libres, que se habían quedado en las poblaciones conquistadas por los cristianos mediante cartas de seguridad y privilegio ${ }^{40}$.

Los monarcas siguientes ya no legan esclavos moros en sus testamentos, lo que no quiere decir que no los tuviesen: hasta 1249, cuando se conquistó el Algarve occidental, se pudo hacer cautivos de guerra e incluso después de esa data se siguió negocian-

\footnotetext{
35 A.C. SOUSA, op. cit., 1946, pp. 407-410.

36 S.D. ARNAUT, A Crise Nacional dos Fins do Século XIV. I: A sucessão de D. Fernando, Coímbra, 1960, pp. 291-295.

37 Este es el único instrumento de últimas voluntades de la reina que conocemos, porque su testamento se ha perdido. J.A.M. NEVES, A «Formosa Chancelaria»: Estudos dos originais da chancelaria de D. Fernando (1367-1383), tesis de Máster, Universidade de Coimbra, 2005, pp. 354-357.

38 Como ya ha notado M.F.L. BARROS, Tempos e espaços de mouros. A minoria muçulmana no reino português (séculos XII a XV), Lisboa, 2007, pp. 29-31.

39 Documentos Medievais Portugueses. Documentos régios. Vol. I - Documentos dos condes portugalenses e de D. Afonso Henriques, A. D. 1095-1185, t. I, Lisboa, 1958, doc. 330, pp. 430-431.

40 M.F.L. BARROS, op. cit., 2007, pp. 40-44.
} 
do esclavos en el mercado ${ }^{41}$. Así, Denis, en su primer testamento, ya citado, menciona moros sin decir cuántos ni de qué tipo. También su nuera Beatriz de Castilla se refiere a siervas y moras en sus testamentos de 1357 y 1358: son sirvientes domésticas a las que la reina libera como acto de piedad ${ }^{42}$.

En lo que toca a animales, Sancho I dejó a su hijo primogénito sus cinco mejores caballos; los otros caballos, las mulas de silla y las acémilas, al maestro y a los frailes de Évora. Al Monasterio de Santa Cruz de Coímbra regaló las yeguas de Soure y los cerdos de Coímbra. Al Hospital de los Cautivos de Santarém sus vacas, ovejas, yeguas, cerdas y cerdos de Santarém. Finalmente, una parte de los ganados de Évora a la familia de Doña Belida y el resto al referido hospital y al obispo de Évora.

Sancho II legó en su primer testamento la mitad de sus acémilas a los frailes de Calatrava y la otra mitad a los frailes de Santiago; en el segundo, no hizo ninguna mención a animales, que también están ausentes del acto de últimas voluntades de su sucesor. Denis, en su primer testamento, movilizó sus bestias, aves y ganados, entre muchos otros bienes, para pagar sus mandas, pero en los siguientes ya no los refiere. Lo mismo pasa con Alfonso IV, Pedro I y Fernando I. Seguramente, los monarcas no dejaron de poseer caballos, mulas, bueyes, cerdos y otros animales: eran necesarios para sus desplazamientos, para hacer la guerra, para participar en fiestas de caballería, para labrar sus campos, para proveer su mesa... Pero, con el desarrollo del comercio y de la vida urbana, su importancia económica se había vuelto mucho menor y, por eso, ya no constituían un legado tan apetecible.

\section{Armamento defensivo y ofensivo}

Si el metal precioso, los esclavos y los animales parecen ser los bienes muebles más apreciados de acuerdo con los testamentos regios de los siglos XII y XIII, algunos objetos de elevado valor simbólico son también citados.

Alfonso Enríquez no transmitió ningún objeto de este tipo a través de sus dos actos de últimas voluntades, pero sabemos que su escudo y su espada se conservaron más allá de su muerte y tuvieron un rol importante en el imaginario nacional desde tiempos inmemoriales. El escudo estuvo clavado en la pared sobre su túmulo en el Monasterio de Santa Cruz de Coímbra y una tradición muy antigua, puesta por escrito en 1416, dice que se caía cada vez que moría un rey de Portugal ${ }^{43}$; la veneración que lo rodeaba se debe, posiblemente, al hecho de haber sido aquel sobre el que Alfonso fue aclamado rey por sus compañeros después de su victoria en la batalla de Ourique, en $1139^{44}$. En cuanto a la espada, guardada también en ese monasterio, fue enviada

41 S.A. GOMES, "Grupos étnico-religiosos e estrangeiros", Portugal em definição de fronteiras, Lisboa, 1996, pp. 309-323.

42 V. LOURENÇO, "O testamento da rainha D. Beatriz", Promontoria, 3-3 (2005), pp. 100-107; A.C. SOUSA, op. cit., 1946, pp. 343-355.

43 A.A. NASCIMENTO, Livro de Arautos. De Ministerio Armorum. Estudo codicológico, histórico, literário, linguístico, Lisboa, 1977, pp. 250-251.

44 J. MATTOSO, "A realeza de D. Afonso Henriques", Fragmentos de uma composição medieval, $2^{\mathrm{a}}$ ed., Lisboa, 1990, pp. 226-228. 
con el escudo, en 1578, al rey Sebastián (1557-1578) que quiso llevar las dos piezas a Marruecos para luchar contra los moros. Según algunos autores, se quedaron ambas olvidadas en el barco y fueron devueltas a Santa Cruz después de la derrota de Alcácer Quibir. Otros sostienen, sin embargo, que se perdieron en la batalla porque no hay registro de su devolución al monasterio y solo a inicios del s. XVIII se empieza a oír hablar de ellas de nuevo, lo que sugiere una falsificación. En realidad, la espada que el Museo Militar de Oporto presenta en nuestros días como habiendo sido sacada del túmulo de Alfonso Enríquez data, con toda la probabilidad, de entre 1578 y $1609^{45}$.

Sancho I, en compensación, legó a su hijo Alfonso II sus armas personales: loriga, lorigón, rodilleras, yelmo y espada ${ }^{46}$. Es poco probable que Alfonso las utilizara porque, por su enfermedad, no fue un rey guerrero como sus antecesores ${ }^{47}$. Tampoco se encuentran trazas de su existencia en los reinados siguientes. En cuanto a Sancho II, en su primer testamento legó mil lorigas a los Templarios. Las lorigas, por la cantidad de metal que requerían, eran muy caras y constituían un regalo muy apreciado entre nobles. Los monarcas a menudo las ofrecían a sus vasallos menos afortunados, recuperándolas después de su muerte a título de luctuosa ${ }^{48}$. No sorprende que Sancho quisiera recompensar de esta manera a los caballeros que le ayudaban en la conquista del reino. Previsiblemente, en su segundo testamento, el desafortunado monarca ya no hizo ninguna referencia a estas piezas de armamiento defensivo.

Los reyes siguientes no transmitieron ningún tipo de armas a sus sucesores ni a otros legatarios en sus actos de últimas voluntades. Sin embargo, para Denis tenemos otro tipo de fuentes que nos dan noticias de armas en la Repostería regia ${ }^{49}$. Sabemos, por ejemplo, que el 10 de abril de 1279, Esteban Eanes, repostero mayor del nuevo rey, recibió de Pedro Eanes, repostero del monarca anterior, además de un gran número de joyas y reliquias de las que hablaremos más tarde, gemas que habían estado engastadas en una espada de Denis: dieciséis rubíes, dos cristales de color, catorce zafiros y dos esmeraldas pequeñas ${ }^{50}$. Una espada "que fue del rey" también fue entregada en ese momento; podemos suponer que era la misma, desnudada de sus piedras de valor ${ }^{51}$. Por el número y calidad de las gemas descritas, se trataría de una espada de aparato y no de combate ${ }^{52}$.

45 Pera guerrejar. Armamento medieval no espaço português, catálogo de la exposición, Palmela, 2000, pp. 330-335.

46 La loriga era una protección para el cuerpo hecha primero de placas de metal fijadas en una base resistente y luego de pequeños eslabones de metal enlazados unos en los otros; solía cubrir los muslos. El lorigón era lo mismo pero más corto y por eso más indicado para el combate a caballo. Dejaba las piernas descubiertas, lo que explica la necesidad de rodilleras, también llamadas brafoneiras. M. BARROCA, "Armamento medieval português. Notas sobre a evolução do equipamento militar das forças cristãs", Pera guerrejar, op. cit., 2000, pp. 41-43 y 56.

47 No se sabe exactamente de qué enfermedad padecía Alfonso II, pero se cree que era afligido por una dermatosis de aspecto semejante a la lepra, que lo hizo corpulento. H.V. VILAR, D. Afonso II, Lisboa, 2005, p. 41 .

48 M. BARROCA, op. cit., 2000, p. 42.

49 Nos referiremos más detalladamente a estos registros más adelante.

50 A.B. FREIRE, "Inventários e contas da casa de D. Dinis (1278-1282)", Arquivo Histórico Português, X (1916), pp. 41-59, especialmente p. 45.

51 Ibid., p. 46.

52 Como sugirió J.A.S.M. PIZARRO, D. Dinis, Lisboa, 2008, n. 3, p. 78. 
Después del 10 de mayo siguiente, el mismo repostero mayor recibió del guarda del almacén de Lisboa veinte espadas, doce perpontos $^{53}$ y diez lorigones ${ }^{54}$. Podría tratarse, una vez más, de armas que el rey tenía de proveer a sus vasallos. Sin embargo, el 23 de marzo de 1280, Esteban Eanes recibió del mismo oficial unas lorigas de caballo con sus riendas que habían pertenecido a Alfonso III y unas lorigas de corpore con sus rodilleras y su almofre postizo que habían sido de otro hombre ${ }^{55}$. En este caso, el rey mismo iría a utilizarlas y a su funcionalidad se juntaba el prestigio de haber pertenecido a un soberano victorioso anterior.

\section{Los objetos suntuarios}

Sancho I fue el primer monarca que enumeró en su testamento algunos objetos suntuarios. A su heredero, el futuro Alfonso II, legó dos anillos que habían sido de su padre Alfonso Enríquez y seguramente tenían un enorme significado simbólico por haber pertenecido al fundador de la monarquía portuguesa ${ }^{56}$. Todos sus otros anillos y sortijas fueron legados a su hija Sancha. Al Monasterio de Alcobaça dejó su capilla (cuya composición desconocemos), una copa de oro para que los monjes hiciesen con ella una cruz y un cáliz, y cien marcos de plata para hacer frontales para los altares de San Pedro y San Agustín. La Iglesia de Santa María de Santarém recibió igualmente cincuenta marcos de plata para un frontal de altar. Además, el monarca ordenó que de una copa de oro con su sobrecopa se hiciesen dos cálices para regalar a las catedrales de Braga y Lisboa.

El mismo Sancho I legó varios textiles y prendas de vestir: 500 morabetinos de paños guardados en el Monasterio de Santa Cruz de Coímbra a todas las personas que había perjudicado de alguna manera; sus paños de Guimarães a su primogénito; y a la infanta Sancha ${ }^{57}$, sin duda su hija preferida porque fue agraciada con más objetos personales ${ }^{58}$, sus cinturones, paños de escarlata y lienzo, pieles y tapices, además de su litera (incluyendo la estructura de madera y sus textiles respectivos).

Alfonso II solo mencionó que quedarían en el Monasterio de Alcobaça las sortijas mayores y menores y los anillos que tuviese en el momento de su muerte. Ni Sancho II ni Alfonso III refirieron joyas o ropas en sus testamentos.

53 Se trataba de jubones forrados que se usaban debajo de las lorigas, para tornarlas menos incómodas y amortecer los golpes del enemigo, o sobre ellas; en este caso, podían tener señales. M. BARROCA, op. cit., 2000, pp. 57-58.

54 A.B. FREIRE, op. cit. (1916), p. 46.

55 Ibid., p. 48. El almofre o almafre era una protección para la cabeza hecha con eslabones metálicos. M. BARROCA, op. cit., 2000, p. 56.

56 Como ya ha señalado M.J.V. BRANCO, D. Sancho I, Lisboa, 2010, p. 277.

57 Nacida c. 1183, Sancha recibió de su padre, además de muchas joyas y prendas, el señorío de la villa de Alenquer. Fundadora del Monasterio de Celas de Coimbra, donde pasó sus últimos días, esta infanta murió en el 13 de marzo de 1229 en olor de santidad y fue beatificada por Clemente XI en 1705. Sobre ella, $c f r$. M.A.F. MARQUES, D. Matilde, D. Teresa, D. Mafalda e D. Sancha. Primeiras infantas de Portugal, Vila do Conde, 2011, pp. 62-72; M.T.N. VELOSO, op. cit., 2000, pp. 82-96.

58 Lo que ya ha sido notado por M.A.F. MARQUES, op. cit., 2011, pp. 64-65. 
En tiempos de Denis, como ya hemos dicho, las fuentes se vuelven súbitamente más numerosas y variadas, haciéndonos conocer más detalladamente sus prendas de valor. Para este rey, no solo tenemos a nuestra disposición un inventario parcial de lo que recibió en el momento de fundación de su Casa sino también los registros de entrada de objetos en su Repostería, Escanciaría y Copa durante los años iniciales de su reinado ${ }^{59}$, además de tres testamentos y un codicilo. ¿Qué nos dicen todos estos documentos?

Para empezar, nos explican cómo se formaba el tesoro de un infante heredero: el 20 de junio de 1278, al constituirle su Casa, Alfonso III donó a Denis la suma de 40.000 libras. La reina Beatriz de Castilla contribuyó también a llenar la Repostería de su hijo, ofreciéndole un conjunto de objetos de plata: una vasija, quince escudillas, dos talladores, cuatro saleros, doce cucharas y un pichel para echar agua en las manos ${ }^{60}$; la vasija tenía señales de águilas y leones, y es posible que hubiera sido un regalo del padre de Beatriz, Alfonso X de Castilla, hijo de Fernando III y Beatriz de Suabia ${ }^{61}$. Tres días antes, la Escanciaría del infante había recibido - no sabemos si del rey o de la reina- siete vasos y seis tagaras de plata ${ }^{62}$ y en la Copa habían sido integrados tres picheles y tres vasos de plata, un vaso y una sobrecopa de plata dorada, más una copa dorada alrededor del borde y del pie ${ }^{63}$.

Al morir Alfonso III en febrero del año siguiente, su vajilla de plata se incorporó al núcleo inicial del tesoro de su hijo: muchos más vasos, picheles, copas con sus sobrecopas, vasijas, escudillas, cucharas, saleros de plata, algunos de ellos trabajados y dorados, vinieron juntarse a los anteriores ${ }^{64}$. Pero, por la misma ocasión, una multitud de otros objetos suntuarios fueron entregados al nuevo rey por el repostero y el tesorero de su padre: decenas de gemas -zafiros, diamantes, rubíes, esmeraldas...engastadas o no en oro, plata y otros materiales; piedras, escorpiones y otros objetos con propiedades curativas; reliquias e imágenes sagradas; tejidos preciosos, cinturones, botones, anillos, camafeos... ${ }^{65}$ Curiosamente, no fue transmitido ninguno de los símbolos mayores del poder regio: ni corona, ni espada, ni cetro. Solo un pendón de oro y plata con "señales del rey" y otro pendón para lanza, en seda blanca, con esas mismas señales ${ }^{66}$. "Señales del rey" también surgen en unas coberturas para caballos, unos escudetes y unos castillos de oropel que el monarca encomienda un poco más $\operatorname{tarde}^{67}$. Y es todo.

Después de esta gran incorporación, la Repostería y la Copa de Denis siguieron recibiendo objetos de valor a lo largo de los dos a cuatro años para los cuales hay

\footnotetext{
59 Se trata del documento referido en la nota 50. Fue estudiado por R.A.G. MELRO, O tesouro de D. Dinis no contexto dos tesouros medievais, tesis de Máster, Universidade de Lisboa, 2010.

60 A.B. FREIRE, op. cit., 1916, pp. 41-42.

61 J.A.S.M. PIZARRO, op. cit., 2008, pp.78-79.

62 A.B. FREIRE, op. cit., 1916, pp. 51-52.

63 Ibid., p. 53.

64 Ibid., pp. 42-44, 52, 53.

65 Ibid., pp. 44-46.

66 También fueron entregados dos pendones "de infantes". Ibid., p. 46.

67 Ibid., pp. 48 y 49.
} 
registros $^{68}$, pero en mucho menor número. En la Repostería entraron un espejo, aros, tagaras y arracadas de plata, cantidades de granos de aljófar y oro, ramos de coral... ${ }^{69}$ En la Copa fueron depositados vasos, copas y picheles de plata, algunos de ellos encomendados por el rey ${ }^{70}$. También hay noticia de salida de objetos, ofrecidos por el monarca a oficiales suyos, a hombres cuya condición desconocemos e incluso a una bailarina (soldadeira $)^{71}$. Lo demás que es registrado es el movimiento corriente de esos dos departamentos de la corte: compras de tejidos, ropas, objetos utilitarios, frutas, vino, especies... ${ }^{72}$

En su primer testamento, ya referido, datado en 1299, Denis moviliza todo el dinero que tiene guardado en las torres de Coímbra, Lisboa y otros lugares, además del oro, plata, anillos, gemas y otros bienes muebles que posee, para pagar sus mandas. Sin embargo, nada de esto es descrito o siquiera enumerado porque se destina a ser entregado a sus testamentarios y vendido por ellos para cumplir sus últimas voluntades. Las únicas piezas que el documento particulariza porque el rey las lega directamente a una casa religiosa - en este caso, al Monasterio de Alcobaça, donde se manda sepultar-, son una cruz grande de plata con gemas para llevar en las procesiones y su capilla personal, cuya composición no detalla, para servir en las celebraciones junto a su tumba.

En su segundo testamento, de 1322, el monarca es un poco más prolijo en la descripción de lo que deja, no ya al Monasterio de Alcobaça sino al de Odivelas, un cenobio de monjas cistercienses que había fundado cerca de Lisboa ${ }^{73}$ y donde había entretanto decidido hacer edificar su monumento funerario ${ }^{74}$ : su capilla (con capas, mantos, vestimentas y dalmáticas) y su cruz grande de plata, que ahora es dorada y tiene igualmente botones dorados. Denis posee, todavía, otra capilla que deja a su hijo heredero Alfonso y parece más suntuosa que la precedente: tiene una gran cruz de oro con un camafeo y gemas, reliquias, barriles de cristal, cruces, majestades y libros ${ }^{75}$. Alfonso es agraciado, además, con la vajilla de oro y plata de su padre (vasos, copas, talladores...), gemas, esclavos moros, caballos y bestias de carga. María, la primogénita de Alfonso ${ }^{76}$, recibe dos relicarios y dos coronas de oro con gemas. En su tercer y último testamento de 1324, sin embargo, Denis reparte estas reliquias y joyas entre su nieta y su nuera, Beatriz de Castilla.

68 El Reposte tiene registros hasta 1281, la Copa hasta 1283.

69 A.B. FREIRE, op. cit., 1916, p. 50.

70 Lo sabemos porque se pagó a los artífices que los produjeron. Ibid., 1916, pp. 49 y 54-55.

71 Ibid., pp. 46 y 54.

72 Ibid., pp. 47-51.

73 H.V.VILAR y M.J.V.B.M. SILVA, "A fundação do mosteiro de Odivelas", Congreso Internacional sobre San Bernardo e o Cister en Galicia e Portugal. Actas, Orense, 1992, pp. 589-601.

74 Sobre el cambio en el lugar de enterramiento del rey, $c f r$. G. ROSSI VAIRO, "O mosteiro de S. Dinis e S. Bernardo de Odivelas, panteão régio (1318-1322)", C. SANTOS (coord.), Família, espaço e patrimonio, Oporto, 2011, pp. 433-448.

75 Algunos de estos objetos litúrgicos y devocionales coinciden con los que Denis recibió del tesoro de su padre en 1279. Por ejemplo, A.B. FREIRE, op. cit., 1916, p. 45.

76 Nacida en 1313, María casará en 1328 con Alfonso IX de Castilla y será la madre de Pedro, el Cruel. Sobre ella, cfr. Marsilio Cassotti, Infantas de Portugal rainhas em Espanha, Lisboa, 2007, pp. 95-121. 


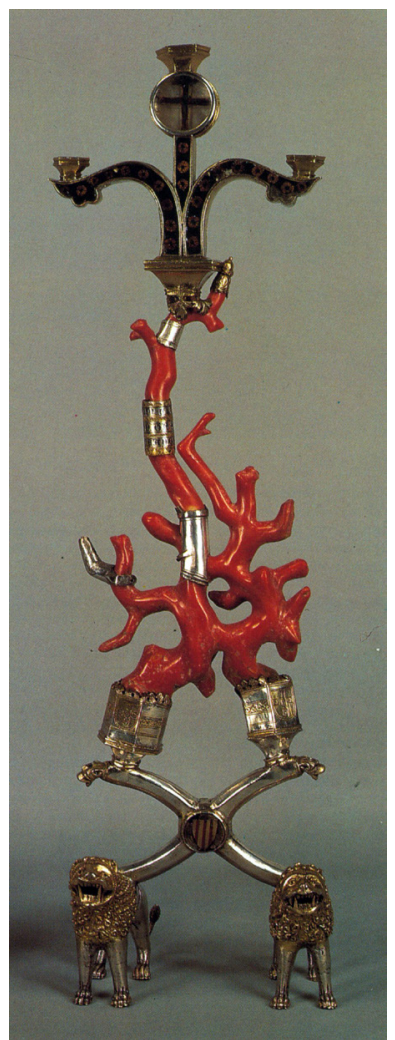

Fig. 3. Relicario de la Cruz de Cristo, s. XIV (Coímbra, Museo Nacional Machado de Castro).

Si los registros y actos de últimas voluntades de Denis nos hacen conocer con más detalle algunos objetos del tesoro regio a los que los testamentos anteriores apenas aludían -vasos y paramentos litúrgicos, joyas-, con su esposa Isabel de Aragón nos encontramos con los propios objetos y no solo con sus descripciones. En efecto, en el Museo Nacional Machado de Castro, en Coímbra, están guardadas algunas de las ofrendas que la Reina Santa hizo al monasterio de Santa Clara de esa ciudad ${ }^{77}$, que refundó y junto al cual vivió retirada del mundo después de la muerte de su marido ${ }^{78}$.

77 Muchos autores han estudiado ya las piezas del impropiamente llamado "tesoro de la reina": A.N. GONÇALVES, O tesouro de D. Isabel de Aragão rainha de Portugal, Coímbra, 1983; F. ALVES y M. MORA, "Tesouros de uma Rainha que o tempo tornou relíquias", Inventário do Museu Nacional de Machado de Castro. Colecção de ourivesaria medieval séculos XII-XV, Coímbra, 2003, pp. 85-91; J. DOMENGE y A. MOLINA, "Les 'nobles i riques ofrenes' d'Isabel de Portugal. Orfebreries de la reina santa", Princeses de terres llunyanes. Catalunya i Hongria a l'edat mitjana, Barcelona, 2009, pp. 307-323; A.M.S.A. RODRIGUES, "The Treasures and Foundations of Isabel, Beatriz, Elisenda, and Leonor. The Art Patronage of Four Iberian Queens in the Fourteenth Century", T. MARTIN (ed.), Reassessing the Roles of Women as "Makers" of Medieval Art and Architecture, vol. 2, Leiden-Boston, 2012, pp. 903-935.

78 Sobre este período de la vida de la reina, $c f r$. M.F. ANDRADE, Isabel de Aragão Rainha Santa, mãe exemplar, Lisboa, 2012, pp. 223-268. 
Entre ellas, figura un relicario con un pedazo de la cruz de Cristo, en plata y coral, con las armas de Aragón y Portugal (Fig. 3). Está constituido por tres piezas distintas: una base de plata con dos leones y una cruz en aspa, sustentando un ramo de coral con aplicaciones de plata, en cuya cumbre se alza la reliquia de la Vera Cruz; se cree que resulta de un montaje de piezas concebidas originalmente para otras funciones ${ }^{79}$.

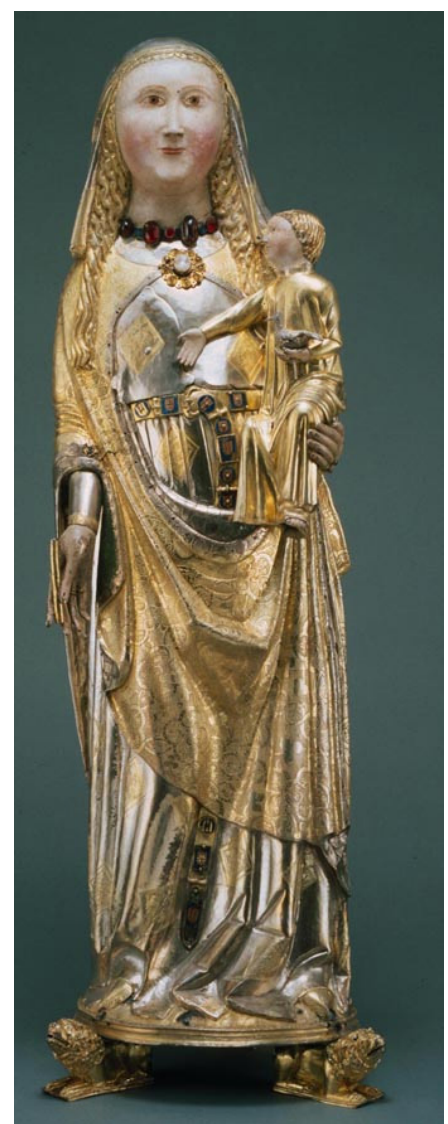

Fig. 4. Imagen-relicario de la Virgen con el Niño Jesús, s. XIV (Coímbra, Museo Nacional Machado de Castro).

En su segundo testamento, datado de 1327, Isabel refiere "la cruz de ligno domini que anda en tres piedras de zafiros perforadas" ${ }^{~} 0$ para legarla a su nieta María. Esta corta descripción es suficiente para constatar que, en esa época, el relicario era muy diferente del que podemos observar en nuestros días. Fue seguramente aún en vida de Isabel -o sea, entre 1327 y 1336- cuando se hizo el nuevo montaje, porque el relicario ostenta las armas de Portugal y Aragón, y no las de Portugal y Castilla, que

79 J. DOMENGE y A. MOLINA, op. cit., 2009, pp. 316-318.

80 A.C. SOUSA, op. cit., 1946, p. 149. 
eran las de María ${ }^{81}$. Lo que no sabemos es por qué acabó en el Monasterio de Santa Clara. ¿No llegó nunca a salir de Coímbra? ¿O fue enviado a María y luego regresó a Portugal? Para aclarar esta cuestión necesitamos profundizar nuestra investigación en fuentes castellanas que no hemos tenido tiempo de consultar hasta el momento.

Otra pieza es una Virgen con el Niño Jesús cuyo cinturón presenta las armas de Aragón (Fig. 4). Este relicario de plata blanca y dorada está actualmente vacío, pero tenía reliquias y se utilizó en tiempos para propiciar la fertilidad. Se cree, en efecto, que a él se refiere Isabel cuando alude a "el tocado, [...] y el velo, y la santa que yo mandaba poner a las novias que casaban de mi casa" de Santa Clara, pidiendo a la abadesa que siga prestándolos a las novias que lo soliciten después de su muerte.
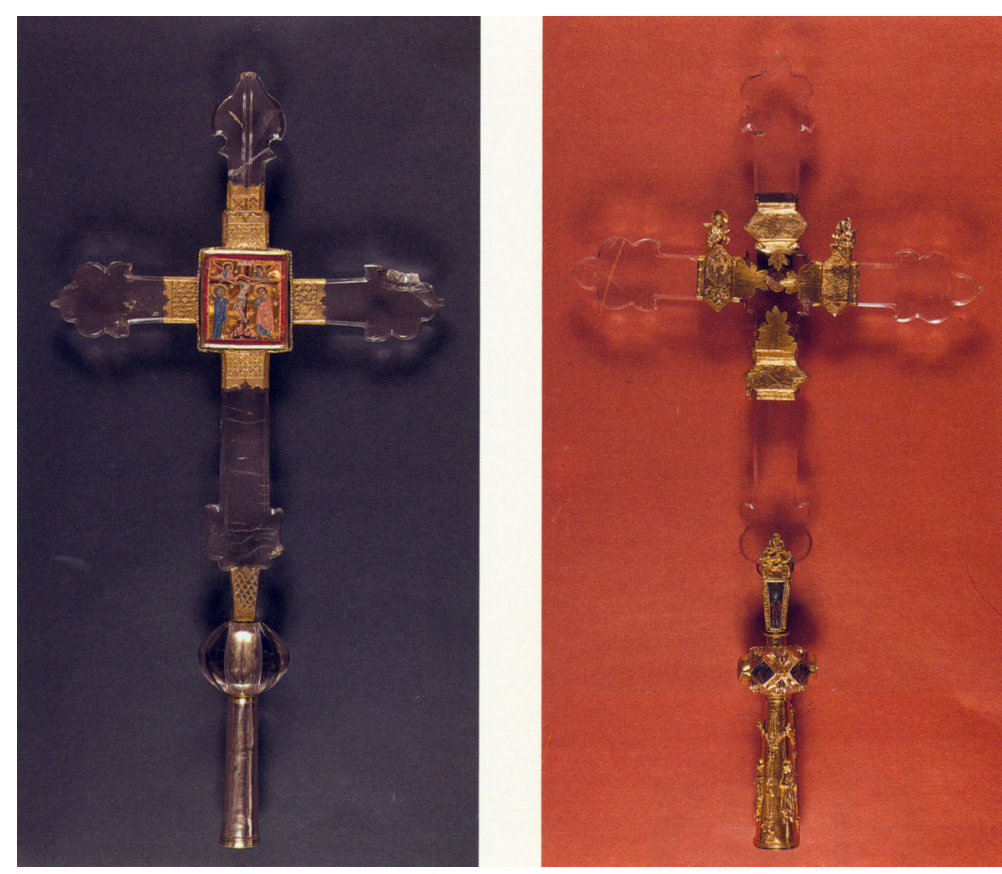

Fig. 5. Cruces de cristal de roca, s. XIV (Coímbra, Museo Nacional Machado de Castro).

La soberana también lega al monasterio, en su último testamento, su capilla personal con todas sus cruces de oro y plata, cálices, turíbulos y vestimentas eclesiásticas. De todo esto, quedan en el museo dos cruces procesionales de cristal de roca (Fig. 5), una con miniaturas de matriz bizantino y la otra con figuras cinceladas y esmaltadas, y una cruz de jaspe con la imagen de Cristo crucificado entre la Virgen María y San Juan, adornada en la base con las armas de Portugal y Aragón (Fig. 6).

81 Por ser hija de Alfonso IV de Portugal y Beatriz de Castilla y, más tarde, esposa de Alfonso IX, como ya referimos.

82 A.C. SOUSA, op. cit., 1946, p. 151. 


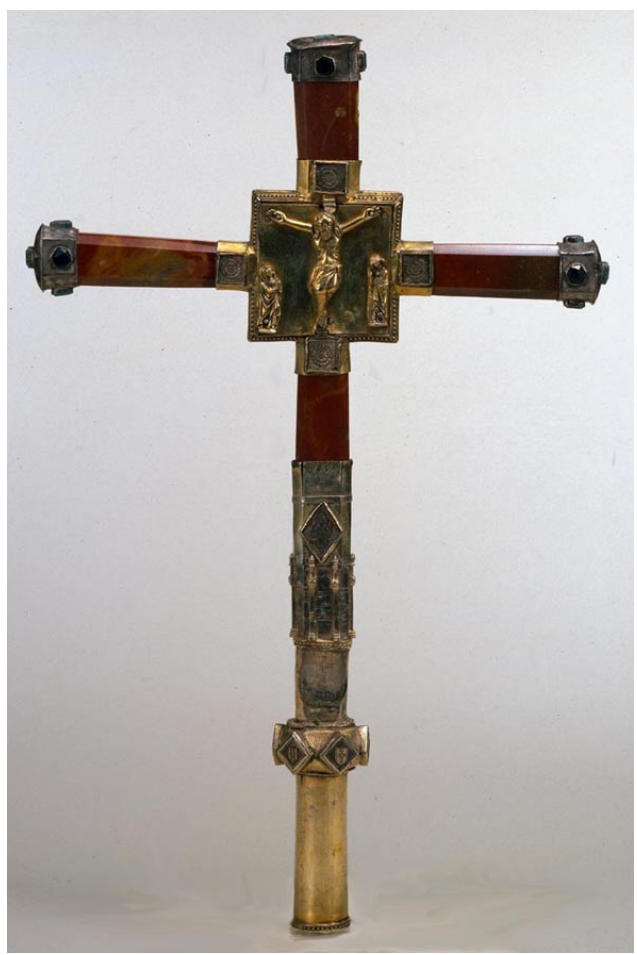

Fig. 6. Cruz de jaspe, s. XIV (Coímbra, Museo Nacional Machado de Castro).

Finalmente, hay un objeto laico en el "tesoro": un collar hecho en el s. XVI con piezas de un cinturón o cadena de la reina (Fig. 7) cuyas flores originales de oro y gemas son muy parecidas al broche de la Virgen. También se le reconocían propiedades mágicas: se creía que facilitaba los partos ${ }^{83}$.

Si estos objetos, y otros que pertenecieron a la Reina Santa, llegaron a Portugal a través de Aragón (aunque pudieron haber sido manufacturados en otros lugares, como es el caso de una de las cruces de cristal de roca que se cree provenir de Vene$\mathrm{cia}^{84}$ ) no se sabe exactamente cuándo sucedió eso. Al casarse, en 1291, Isabel trajo como dote, según dice el anónimo autor de su Vita, "grande vajilla de plata" ${ }^{85}$. Más tarde, siguió recibiendo regalos de su familia, como cuando fue a encontrarse con su hermano Jaime II en Tarazona en $1304^{86}$. Pero la reina también pudo hacer encargos

83 A.N. GONÇALVES, op. cit., 1983, p. 15.

84 J. DOMENGE y A. MOLINA, op. cit., 2009, pp. 313-314.

85 "Relaçam da vida da gloriosa Santa Isabel Rainha de Portugal, tresladada de hum livro escrito de maõ, que esta no Conuento de S. Clara de Coimbra, \& que serue para vários capítulos desta historia, \& da subsequente", F. BRANDÃO, op. cit., 1980, Apêndice, p. 498.

86 En esta ocasión, no fue solo Isabel sino también Denis y los infantes Alfonso y Constanza quienes recibieron regalos del rey de Aragón: guantes, tejidos, Agnus Dei, copas, picheles... J.E. MARTÍNEZ FERRANDO, "La Cámara Real en el reinado de Jaime II (1291-1327). Relaciones de entradas y salidas de objetos artísticos", Anales y Boletín de los Museos de Arte de Barcelona, 11 (1953-1954), doc. 8, pp. 14-15. 
por su propia iniciativa: se cree que la Virgen con el Niño fue hecha a petición suya durante los primeros ocho años de su matrimonio en que no logró quedar embaraza$\mathrm{da}^{87}$.

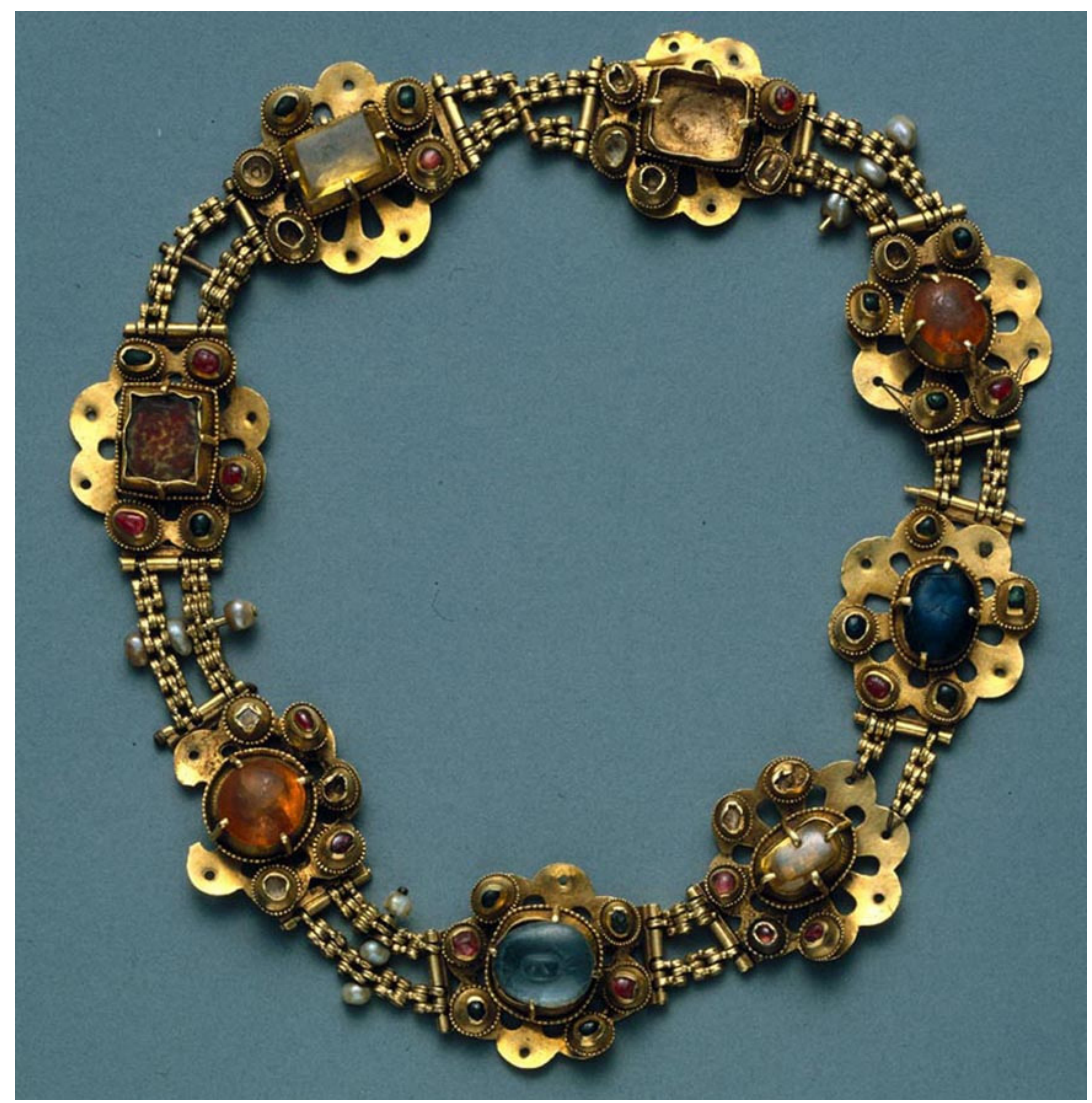

Fig. 7. Collar de oro y gemas; base del s. XIV y montaje del s. XVI (Coímbra, Museo Nacional Machado de Castro).

Los testamentos de Isabel de Aragón nos revelan, todavía, muchos más objetos suntuarios que los que se han conservado hasta nuestros días. En el primero, de $1314^{88}$, la soberana dejó todas sus gemas, aljófar, coronas y broches a su marido y a su hijo, para que cumplieran por ellos sus mandas; legó a Alfonso su vajilla de plata y su copa de oro; legó también a los monasterios de Alcobaça y Odivelas sendas capillas con sus cruces, reliquias y vestimentas, sin más detalles. Sin embargo, en el último, la reina fue mucho más locuaz: legó a su nuera Beatriz de Castilla su corona con esmeraldas, a condición de que esta la dejase, a su muerte, a su hija María. La

87 J. DOMENGE y A. MOLINA, op. cit., 2009, p. 311.

88 A.C. SOUSA, op . cit., 1946, pp. 144-147. 
misma María recibió directamente de su abuela otra corona pequeña con piedras perforadas, un broche redondo, unos pendientes con águilas, el relicario del Santo Leño del que ya hablamos y otros dos relicarios hoy desaparecidos. Leonor de Castilla, la otra nieta de Isabel ${ }^{89}$, recibió solamente una corona con rubíes y unos pendientes con piedras y figuras.

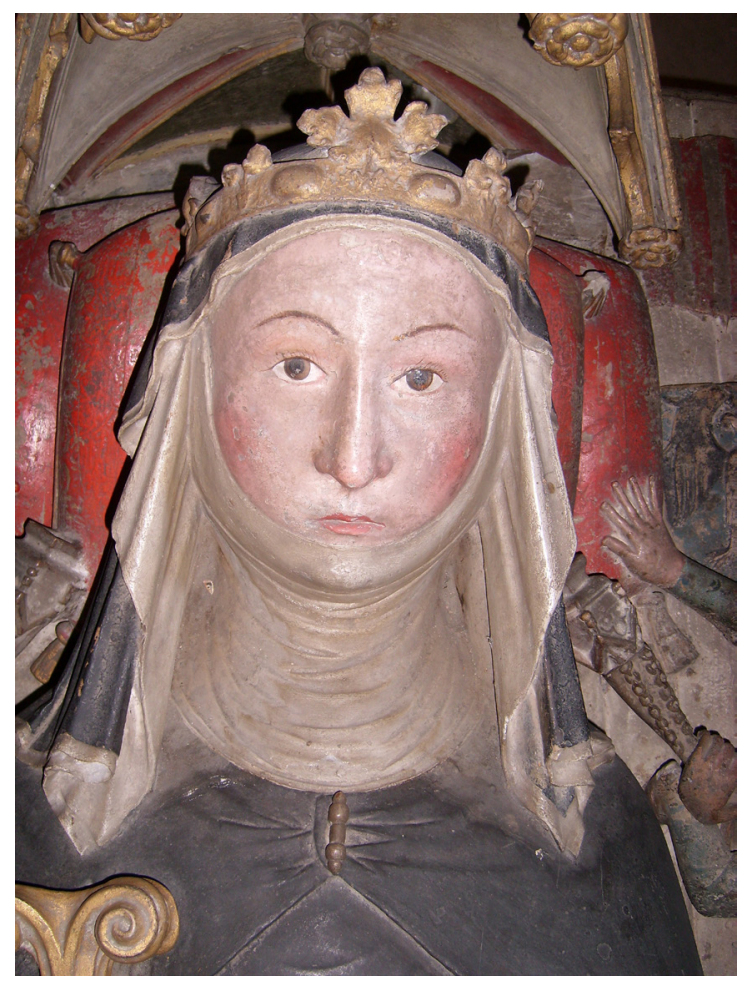

Fig. 8. Yacente de la reina Isabel de Aragón, c. 1330 (Coímbra, Monasterio de Santa Clara-a-Nova).

Ninguna corona de estos tiempos ha sobrevivido en Portugal, pero disponemos de dos representaciones que nos acercan a cómo pudieron ser: las que figuran en los monumentos funerarios de Isabel de Aragón (Fig. 8) y de su nieta Isabel de Portugal (Fig. 9) ${ }^{90}$, hechos por Maestre Pedro, un escultor venido de Aragón alrededor de 1330 a petición de la reina ${ }^{91}$. Se trata, en ambos casos, de coronas abiertas y bajas, de oro o plata dorada, poco trabajadas y con pocas o ningunas gemas, similares a la que figura

89 Nacida en 1307 e hija de su hija Constanza y de Fernando IV de Castilla, esta infanta fue la segunda esposa de Alfonso III de Aragón. Isabel tuvo una tercera nieta que fue también reina de Aragón, Leonor, de quien enseguida hablaremos, pero esta nació en el año siguiente, 1328.

90 Agradecemos a nuestra alumna Clara Ribeiro la posibilidad de reproducir las fotografías que ha hecho para Género e representação: a indumentária femenina nos jacentes portugueses dos séculos XIII a XV, tesis de Máster, Universidade de Lisboa, 2014.

91 C.A.F. ALMEIDA y M.J. BARROCA, História da Arte em Portugal - O gótico, Lisboa, 2002, p. 225. 
en el yacente de Blanca de Anjou, la cuñada de la reina Isabel, en Santes Creus ${ }^{92}$, o sea, probablemente, de modelo aragonés.

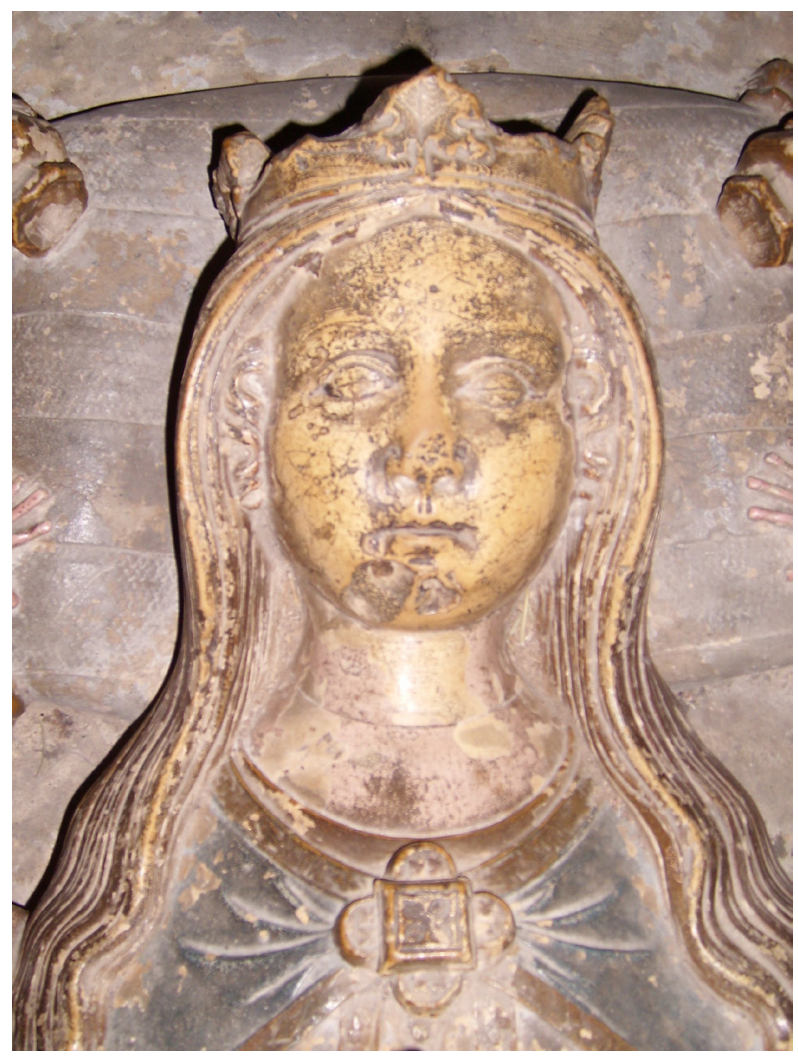

Fig. 9. Yacente de la infanta Isabel de Portugal, c. 1330 (Coímbra, Monasterio de Santa Clara-a-Nova).

A pesar de no existir ceremonia de coronación en la monarquía portuguesa ${ }^{93} \operatorname{los}$ reyes también eran representados coronados en sus túmulos, al igual que en las monedas, los sellos, etc. ${ }^{94}$ Sin embargo, al revés de lo que se pasa con las reinas, ninguno de los actos de últimas voluntades de los soberanos refiere la transmisión de alguna corona al heredero, y solo Denis, como hemos visto, dejó dos, presumiblemente femeninas, a su nieta María.

92 C.V. FERNANDES, "Maestre Pero y su conexión con el arte de la Corona de Aragón (La renovación de la escultura portuguesa en el siglo XIV)", Boletín del Museo e Instituto “Camón Aznar”, LXXXI, (2000), p. 247 y fig. 1 , p. 257.

93 Cfr. J. MATTOSO, “A coroação dos primeiros reis de Portugal”, Naquele tempo. Ensaios de história medieval, Lisboa, 2000, pp. 501-518, y P. LINEHAN, "Utrum reges Portugallie coronabantur annon”, The Processes of Politics and the Rule of Law, Aldershot, 2002, VI, pp. 389-410 y Addenda, pp. 1-4.

94 Véanse, por ejemplo, el morabetino de Sancho I (Fig. 1) y el yacente de Pedro I (Fig. 2). 
Los testamentos de Beatriz de Castilla ${ }^{95}$ están llenos de informaciones no solo sobre sus objetos de lujo sino también sobre cómo los cobró, revelando la intensidad de la circulación de alhajas y prendas en el seno de las familias reales. El último fue dictado en 1358, después de las muertes recientes de su marido y su hija María (en 1357), pasados diez años de las de su otra hija Leonor, reina de Aragón (1348) y de su nuera Constanza Manuel (1349), ambas víctimas de la Peste Negra, y muchos años después de las de su suegra Isabel de Aragón (1336), su hermano Felipe de Castilla (1327) y su madre María de Molina (1321). De esta, Beatriz conserva una gran esmeralda y otra esmeralda "de virtud", o sea con poderes curativos, que deja a su hijo, el futuro Pedro I, con la condición de que tras él quede siempre en las manos del rey o del heredero del trono; encontramos aquí el embrión de lo que podríamos llamar las "joyas de la corona", porque es la primera vez que tal condición acompaña un legado. De Felipe, le queda un cinturón en plata esmaltada. De la Reina Santa, muchas cuentas de oro, pero no encontramos rastro de la corona que esta le dejó en su testamento. De Constanza Manuel, también le quedaron cuentas de oro y una cruz de oro con un rubí y cuatro zafiros.

De su marido Alfonso IV, la reina heredó una copa de oro con esmaltes; otra copa de oro con un zafiro; un camafeo con un león; otro camafeo con caras de hombres gordos; varios anillos con piedras preciosas y un cinturón de oro. De su hija María, una moneda de oro con esmaltes y un castillo decorado con piedras, aljófar y camafeos. De Leonor, muchas cuentas de coral; una copa con su sobrecopa con la figura del Caballero del Cisne; una jarra esmaltada pequeña; dos anillos, uno con una esmeralda y otro con un rubí; una serpiente con escorpiones de plata y coral, y una arqueta. Todos estos bienes fueron legados por Beatriz a su hijo Pedro I o a sus nietos: el futuro rey Fernando I y la infanta María, hijos de Constanza Manuel; Juan, Denis y Beatriz, hijos de Inés de Castro.

También fue Leonor quien ofreció a su madre Beatriz el paño adornado con leones y castillos que esta pidió fuese utilizado como su lienzo mortuorio. Lo curioso es que, cuando Leonor se casó con Pedro IV de Aragón en 1347, su padre le regaló varias joyas que habían sido empeñadas por María de Aragón a un mercader de Lisboa cuando esta infanta vivió en Portugal, acompañando a su hija Blanca de Castilla, prometida del heredero del trono ${ }^{96}$. Se trataba de una corona de oro con cuatro esmeraldas, tres rubíes, seis zafiros y aljófar; copas de oro, plata, nácar o cristal, simples, incrustadas de piedras o con esmaltes; picheles de cristal con pies de plata dorada; cucharas de plata; una taza de plata con castillos y águilas; un turíbulo con cadenas. También habían sido empeñados algunos accesorios: un cinturón esmaltado y bordado a hilo de plata; otro cinturón bordado a seda e hilo de oro; un sombrero rojo decorado con

95 De esta reina, se conocen tres: el primero data de 1349 y es referido en el codicilo que lo altera, en 1354, editado por A.C. SOUSA, op. cit., 1946, pp. 341-343; el segundo, datado de 1357, fue publicado por V. LOURENÇO, op. cit. (2005), pp. 100-107; y el tercero, de 1358, también fue editado por A.C. SOUSA, op. cit., 1946, pp. 343-355. Estos testamentos fueron estudiados por V. LOURENÇO, op. cit. (2005), pp. 81-99; H. FERNANDES y L.U. AFONSO, "Do luxo à economia do dom: em torno do tesouro da rainha D. Beatriz (1349-1358), Clio, 16/17 (2008) pp. 363-394; A.M.S.A. RODRIGUES, op. cit., 2012.

96 Sobre esta infanta aragonesa y su hija, cfr. A.P.M. COSTA, op. cit., 2012, pp. 258-272 y 302-338. 
aljófar y piedras coloridas. Todo esto ascendió a 2.100 libras portuguesas ${ }^{97}$ y Leonor se lo llevó de vuelta a Aragón, junto con sus muchos efectos personales de origen portugués y castellano-leonés.

Cuando murió, poco más de un año después de haber llegado a su nuevo reino, Leonor no tenía hijos y, aparte de una jarra de oro y una arqueta que reservó a su padre (¿será la misma que figura, años más tarde, en el testamento de Beatriz?), y la mejor joya de su tesoro que legó a su madre, pudo dejar todos sus bienes muebles por alma ${ }^{98}$. De lo que fue vendido - mulas, arcas, prendas de vestir, objetos de devoción, ramos de coral, joyas, vajilla de plata...- quedaron varios libros de cuentas ${ }^{99}$ que están siendo estudiados por una alumna de doctorado ${ }^{100}$ que pronto presentará sus conclusiones y nos permitirá saber más sobre estos objetos suntuarios que viajaban de un reino a otro en las dotes de las infantas, eran empeñados en momentos de apuro financiero, se enviaban como regalos a hermanos y cuñados, y siguen maravillándonos con su belleza cuando, afortunadamente, se han conservado hasta nuestros días.

Como conclusión, podemos decir que, en el inicio del período considerado, no había distinción entre los medios financieros de la monarquía y los bienes muebles personales del rey. El monarca los reunía todos en el mismo sitio -primero en instituciones religiosas como los monasterios Alcobaça y Santa Cruz, o las sedes de las órdenes militares del Templo, del Hospital y de Évora, después en las torres de los castillos de las ciudades donde residía con más frecuencia, Coímbra y Lisboa- y los utilizaba de igual manera para beneficiar a sus fieles y servidores, hacer la guerra, pagar sus deudas y sufragar su alma. En esa primera época, la moneda y los metales preciosos constituían la principal riqueza del soberano, que también valoraba mucho a los animales y a los moros cautivos.

En un segundo momento, la moneda de oro y plata casi desapareció de los testamentos, el ganado y los esclavos también, revelando que los monarcas empezaron a distinguir los bienes de la corona de los suyos propios. En compensación, surgen con creciente frecuencia los objetos suntuarios que constituyen el tesoro real propiamente dicho: cruces, vasos litúrgicos, relicarios, copas y sobrecopas, telas ricas, anillos, broches, coronas... Estas últimas, sin embargo, son las únicas insignias de la realeza que las fuentes documentales más tardías nos revelan y parecen ser una "cosa de mujeres". Necesitamos profundizar esta investigación para esclarecer este y otros puntos en que la realidad portuguesa parece alejarse de la de las monarquías vecinas.

\footnotetext{
97 A.C. SOUSA, op. cit., 1946, pp. 380-382.

98 A.M.S.A. RODRIGUES, "Un destin interrompu: Aliénor de Portugal, brève reine d'Aragon (13471348)", Études Roussillonnaises, XXV (2013), pp. 93-95.

99 Archivo de la Corona de Aragón, Real Patrimonio, Maestre Racional, vols. 2256, 2257, $2258,2259$.

100 Adriana Romba de Almeida, A Queen in the Mirror. The Wordly Possessions of Leonor of Portugal, Queen of Aragon (1347-1348), tesis de doctorado en curso.
} 